\title{
Time to experiment: a response
}

Mike Davis* and Kate Denning**

*Learning Technology Research Institute, University of North London **Research and Graduate School of Education, University of Manchester

email:mike.davis@unl.ac.uk

It is with some pleasure that we were given the opportunity to offer this paper for commentary and we are grateful for the efforts made by readers to help us to refine our thinking. Given the constraints of space, we will respond to the main comments in turn. We plan to submit a more considered and elegant paper to a future edition when we have worked more on our model.

As we are aware, the use of learning technologies is untheoretical, although informed by a number of theories from a variety of disciplines. Part of our thinking was based on a desire to integrate some of these and work towards explanations for what we had seen going on in the courses that we were involved in teaching. That this is recognized in the commentary is much appreciated.

Our failure to describe action science in more detail was a product of pressure on space. Briefly, action science, was developed as 'the science of interpersonal action' and is 'centrally concerned with the practice of intervention' (Argyris, Putnam and Smith, 1986: 35 ) into frequently mismatched espoused theories and theories in use. The development of skill in action science relates to capacity for reflective action; not only reflection on action but also reflection on reflection in action. This is achieved by making theories of action explicit through the presentation and interrogation of case studies.

The absence of examples from the data was the product of limitations on space. Other papers we have written for conferences make more explicit the relationship between our thinking and the data (see for example Davis and Denning, 2000). 
The paper does little justice to the complexities of Bion's thinking about basic assumption groups and work groups, but Table 1 may help. Bion's view was that groups had the capacity to function in any of the three basic assumption groups or to be a work, or sophisticated group, but that the two types are mutually exclusive.

\begin{tabular}{ll}
\hline Basic assumption groups & Work groups \\
\hline $\begin{array}{l}\text { based on fantasy } \\
\text { impulsive }\end{array}$ & $\begin{array}{l}\text { in touch with reality } \\
\text { task-specific } \\
\text { dependent on leader } \\
\text { uncritical }\end{array}$ \\
shared leadership in service of the task \\
critical \\
task-avoiding & reflective \\
no desire to test consequences & high level of commitment to the task \\
no patience with enquiry & conclusions tested with reality \\
great insistence on feeling & questions how to achieve goal \\
does not learn from experience & seeks for knowledge \\
resists change & learns from experience \\
cliché-ridden & seeks change \\
anonymous & dynamic \\
ruthless & ownership of responsibility \\
ahistoric & collegiate and interdependent \\
valency & aware of passage of time \\
\hline
\end{tabular}

Table 1: Distinguishing between basic assumption and work groups

Situated learning was not pursued in anything like the depth it deserved and we are working on another paper that makes more explicit its relationship to computer-mediated learning, particularly in the context of action science. It was included, however, to demonstrate that we were aware of its potential implications for groups working collaboratively through personal case studies. The role of the online tutor here is of considerable importance and the paper failed to do justice to this and its relationship to the development of expertise.

Our use of the word 'scaffolding' is firmly based on the work of Vygotsky and we did not mean to imply merely the restricted use of students building on one another's comments. Indeed, this relates to our thinking about the role of the online tutor that we have explored elsewhere (see for example Denning and Davis, 2000).

The title of the paper was deliberately playful, indicating the tentative nature of our conclusions. For us, at least, and perhaps for other readers, our thinking may inform future speculation about the nature of the online learning environment.

Neither of the authors is a psychologist but we regard some psychological literature as helpful in exploring the learning environments in which we have worked. We consider Wilfred Bion's work to be particularly important in thinking about the nature of groups and their impact on people's collaborative experiences. His theorizing led to the creation of the Tavistock Institute and to the considerable insights that this organization has given to social interaction in both the home and the workplace. 
Our use of the $2 \times 2$ matrix has clear limitations and we have struggled to make it work to our satisfaction. It did, however, enable us to characterize what we saw as some stereotypical outcomes of creating learning environments in cyberspace. This represents the provisional nature of our thinking. The suggestion of spider diagrams is extremely helpful and we will return to this in our future paper.

The value of the model for us is that it helps to shape our, often muddled, reactions to the problem of why some groups were successful and others less so. It is not a definitive statement and some of the comments made by readers have indicated a way forward.

\section{References}

Argyris, C., Putnam, R. and Smith, D. (1986), Action Science, San Francisco: Jossey-Bass.

Bion, W. (1996), Experiences in Groups and Other Papers, London: Tavistock.

Davis, M. and Denning, K. (2000), 'Online learning: frontiers in the creation of learning communities', Proceedings of the Networked Learning 2000 Conference, University of Lancaster.

Denning, K. and Davis, M. (2000), 'Computer mediated communication in adult education', in D. Watson and T. Downes, Communications and Networking in Education, Kluwer: Amsterdam. 